\title{
Optimization and shelf life of a low-lactose yogurt with Lactobacillus rhamnosus HN001
}

\author{
A. Ibarra, ${ }^{*} \dagger^{1}$ R. Acha, $\neq$ M.-T. Calleja, $\ddagger$ A. Chiralt-Boix, $†$ and E. Wittig ${ }^{\star}$ \\ *Departamento de Análisis Sensorial y Desarrollo de Productos, Universidad de Chile, Avda. Vicuña Mackenna 20, Santiago, Chile \\ †Departamento de Tecnología de los Alimentos, Universidad Politécnica de Valencia, 46071, Valencia, Spain \\ ¥Soprole SA, Avda. José Pedro Alessandri 10800, Santiago, Chile
}

\section{ABSTRACT}

Lactose intolerance results in gastrointestinal discomfort and the malabsorption of certain nutrients, such as calcium. The replacement of milk with low-lactose and probiotic-enriched dairy products is an effective strategy of mitigating the symptoms of lactose intolerance. Lactobacillus rhamnosus HN001 (HN001) is a safe, immunity-stimulating probiotic. We have developed a process to increase the hydrolysis of lactose and HN001 growth in yogurt versus $\beta$-galactosidase $(\beta \mathrm{G})$ concentration and enzymatic hydrolysis time (EHT) before bacterial fermentation. The objective of this study was to optimize the conditions by which yogurt is processed as a function of $\beta \mathrm{G}$ and EHT using a multifactorial design, with lactose content, HN001 growth, process time, and sensory quality as dependent variables. Further, the shelf life of the optimized yogurt was evaluated. In the optimization study, polynomials explained the dependent variables. Based on Pearson correlation coefficients, HN001 growth correlated positively with the hydrolysis of lactose. However, low lactose content and high HN001 count increased the fermentation time and lowered the sensory quality. The optimized conditionsusing polynomials to obtain yogurt with $>1 \times 10^{7} \mathrm{cfu}$ of $\mathrm{HN} 001 / \mathrm{mL},<10 \mathrm{~g}$ of lactose/L, and a minimum overall sensory quality of 7 on the Karlsruhe scale-yielded a theoretical value of 910 neutral lactose units $/ \mathrm{kg}$ for $\beta \mathrm{G}$ and $2.3 \mathrm{~h}$ for EHT, which were validated in an industrial-scale assay. Based on a shelf-life study at 3 temperatures, the hydrolysis of lactose and the growth of HN001 continue during storage. Arrhenius equations were developed for the variables in the shelf-life study. Our results demonstrate that it is feasible to develop a low-lactose yogurt to which HN001 has been added for lactose-intolerant persons who wish to strengthen their immune system.

Key words: lactose intolerance, $\beta$-galactosidase, probiotic, multifactorial design

Received October 15, 2011.

Accepted March 18, 2012.

${ }^{1}$ Corresponding author: alvin.ibarra@gmail.com

\section{INTRODUCTION}

Lactose intolerance is the inability to digest significant amounts of lactose due to a lack of the required enzyme lactase in the digestive system (Swagerty et al., 2002). Lactose malabsorption in the small intestine results in gastrointestinal discomfort (Swagerty et al., 2002), causes calcium malabsorption, and increases the risk of osteopenia (Laaksonen et al., 2009; Wilt et al., 2010). Strategies to reduce the symptoms of lactose intolerance include the replacement of milk with lactosehydrolyzed milk or yogurt and the use of probiotics (Zhong et al., 2004; Shaukat et al., 2010).

Of the many benefits that are associated with the consumption of probiotics, modulation of the immune system has received the most attention (Gill and Prasad, 2008). Several animal and human studies have provided unequivocal evidence that specific strains of probiotics stimulate and regulate several aspects of natural and acquired immune responses (Gill and Prasad, 2008). However, significant gaps remain with regard to the mechanisms by which these probiotics modulate immune function (Gill and Prasad, 2008).

Many species of lactobacilli-gram-positive, nonspore-forming rods, and catalase-negative - are classified as probiotic lactic acid bacteria (LAB). The most common probiotic lactobacilli species are Lactobacillus acidophilus, Lactobacillus salivarius, Lactobacillus casei, Lactobacillus plantarum, Lactobacillus fermentum, and Lactobacillus brevis (Mikelsaar et al., 1998). Dietary consumption of probiotic LAB in a milk-based diet could benefit consumers by stimulating their immune systems (Gill et al., 2001a).

Lactobacillus rhamnosus HN001 (hereafter, HN001) is a safe, immunity-inducing probiotic LAB that does not degrade gastric mucin and does not affect spontaneous platelet activation or aggregation (Gill et al., 2000; Zhou et al., 2000a,b, 2001, 2005; Gill and Rutherfurd, 2001). This probiotic increases the production of $\mathrm{T}$ helper (Th) 1 and Th2 cytokines in antigen-primed mice (Cross et al., 2002) and boosts the immunity of mice against Escherichia coli O157:H7 and Salmonella typhimurium infection (Gill et al., 2001b; Shu and Gill, 
2002). The administration of HN001 to mice enhances the spleen cell response to concanavalin A and lipopolysaccharide (Gill et al., 2000). Splenocytes from mice that are given HN001 also produce significantly higher amounts of interferon- $\gamma$ on stimulation with concanavalin A (Gill et al., 2000).

In humans, the dietary consumption of HN001 in a base of low-fat milk or lactose-hydrolyzed low-fat milk has been shown to upregulate systemic cellular immune responses in middle-aged and elderly volunteers (Sheih et al., 2001). Further, supplementation with HN001 during pregnancy can influence fetal immunity and immunomodulatory factors through breast milk (Prescott et al., 2008) and substantially reduce the cumulative prevalence of eczema (Wickens et al., 2008).

Our aim was to develop a low-lactose yogurt with HN001 for lactose-intolerant persons who wish to strengthen their immune system. We have developed a process to improve the hydrolysis of lactose and the growth of HN001 in yogurt, the scheme for which is shown in Figure 1. In this procedure, the formulation of yogurt without cultures is hydrolyzed for a period, called the enzymatic hydrolysis time (EHT), during which lactose is partially degraded by $\beta$-galactosidase (及G; EC 3.2.1.23), with optimum activity at approximately pH 6.5 and $37^{\circ} \mathrm{C}$. Subsequently, microbial fermentation starts by inoculation of the yogurt culture (Streptococcus salivarius ssp. thermophilus, and Lactobacillus delbrueckii ssp. bulgaricus) with the HN001 culture. The total process time (TPT) ends when the $\mathrm{pH}$ reaches 4.6. During the TPT, the supplemented and bacterially produced $\beta \mathrm{G}$ hydrolyzes lactose.

In this study, we optimized the process by which yogurt is cultured as a function of the concentration of $\beta G$ in neutral lactase units (NLU) per kilogram and EHT in hours to maximize its overall sensory quality, minimize its lactose content, and increase the growth of HN001. In addition, we evaluated the shelf life of the optimized yogurt.

\section{MATERIALS AND METHODS}

\section{Optimization}

A multifactorial design $\left(2^{2}+\alpha\right.$, where $\left.\alpha=1.4147\right)$ was chosen (Moskowitz, 1983), comprising 9 experimental points with 2 repetitions in the center, creating 10 assays. The matrix solution of this model generates a type 1 polynomial:

$$
\mathrm{V}=\mathrm{K}_{0}+\mathrm{K}_{1} \mathrm{X}+\mathrm{K}_{2} \mathrm{Y}+\mathrm{K}_{3} \mathrm{XY}+\mathrm{K}_{4} \mathrm{X}^{2}+\mathrm{K}_{5} \mathrm{Y}^{2},
$$

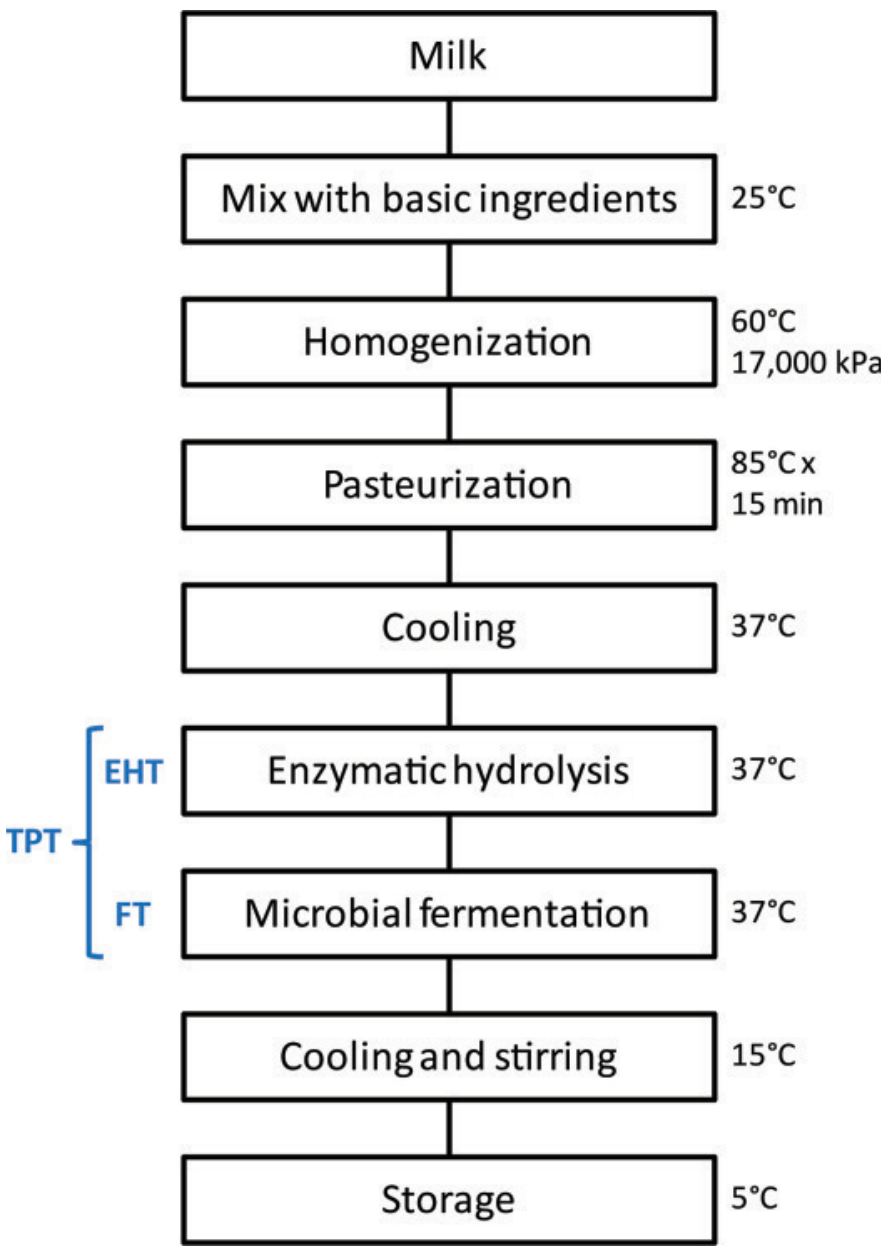

Figure 1. Flowchart of production of a low-lactose yogurt with Lactobacillus rhamnosus HN001. Each unitary operation indicates key parameters, such as temperature, pressure, and time, when relevant. $\mathrm{TPT}=$ total process time for hydrolysis by addition of $\beta$-galactosidase and fermentation with cultures Streptococcus salivarius ssp. thermophilus, Lactobacillus delbrueckii ssp. bulgaricus, and Lb. rhamnosus HN001; $\mathrm{EHT}=$ enzymatic hydrolysis time; $\mathrm{FT}=$ fermentation time. Color version available in the online PDF.

where $\mathrm{V}$ is the dependent variable, $\mathrm{X}$ and $\mathrm{Y}$ are the independent variables, and $\mathrm{K}$ represents the coefficients of the polynomial (Moskowitz, 1983).

The ranges of optimization of the 2 independent variables - concentration of $\beta \mathrm{G}$ and EHT - are shown in Table 1. They were optimized as a function of 4 parameters, which generated 13 dependent variables:

I. Lactose: (1) lactose content after fermentation $(\mathrm{g} / \mathrm{L})$, and $(2)$ lactose hydrolysis rate $(\%)$, defined as

Lactose hydrolysis rate $=\mathrm{L}_{2} \cdot \mathrm{L}_{1}^{-1} \cdot 100$, 
Table 1. Levels of the independent variables $\beta$-galactosidase $(\beta G)$ and enzymatic hydrolysis time $(\mathrm{EHT})$ in the $2^{2}+\alpha$ model (where $\alpha=1.4147$ ) that generated 10 experimental assays ${ }^{1}$

\begin{tabular}{lccccc}
\hline $\begin{array}{l}\text { Independent } \\
\text { variable }\end{array}$ & $-\alpha$ & -1 & 0 & +1 & $+\alpha$ \\
\hline$\beta \mathrm{G}\left(\mathrm{NLU}^{2} / \mathrm{kg}\right)$ & 293 & 500 & 1,000 & 1,500 & 1,707 \\
$\mathrm{EHT}(\mathrm{h})$ & 1.29 & 1.50 & 2.00 & 2.50 & 2.70 \\
\hline
\end{tabular}

${ }^{1}$ This model allowed us to obtain type 1 polynomials to optimize the low-lactose yogurt with Lactobacillus rhamnosus HN001 as a function of its lactose content, probiotic growth, process time, and sensory quality.

${ }^{2} \mathrm{NLU}=$ neutral lactase units.

where $\mathbf{L}_{1}$ is the initial concentration of lactose in the mix before the $\beta G$ addition, and $\mathbf{L}_{2}$ is the lactose content after fermentation.

II. HN001: (3) final count after fermentation (cfu/ $\mathrm{mL}$ ), and (4) growth rate, defined as

$$
\text { Growth rate }=\mathrm{R}_{2} \cdot \mathrm{R}_{1}^{-1}
$$

where $\mathbf{R}_{\mathbf{1}}$ is the initial concentration of HN001 at inoculation and $\mathbf{R}_{2}$ is the final count of HN001 after fermentation.

III. Process time: (5) fermentation time (h) and (6) total process time $(\mathrm{h})$, defined as (see Figure 1 )

$$
\text { Total process time }=\mathrm{EHT}+\mathrm{FT},
$$

where FT is the fermentation time.

IV. Sensory quality: (7) color, (8) appearance, (9) aroma, (10) flavor, (11) texture, (12) residual flavor, and (13) overall quality.

Once the polynomials of these dependent variables were obtained, the concentration of $\beta \mathrm{G}$ and the EHT were optimized as a function of lactose content $\left(\mathrm{L}_{2}\right)$, final HN001 count $\left(\mathrm{R}_{2}\right)$, and overall quality.

\section{Sample Preparation}

For the optimization study, 10 yogurt samples (1 kg each) were prepared (Figure 1), based on the selected multifactorial design. The ingredients of the basic mix (Table 2) were combined and stirred at $25^{\circ} \mathrm{C}$ in stainless steel reactors, and the mixtures were heated individually in a water bath to $60^{\circ} \mathrm{C}$ and homogenized at $17,000 \mathrm{kPa}$ (APV/Rannie, SPX, Charlotte, NC). Next, the mixtures were pasteurized individually at $85^{\circ} \mathrm{C}$ for $15 \mathrm{~min}$ and cooled to $37^{\circ} \mathrm{C}$. At this stage, a sample was taken to determine the initial content of lactose $\left(\mathrm{L}_{1}\right)$.

Then, $\beta G$ (Maxilact LX5000; DSM, Heerlen, the Netherlands) was added with a sterile $1 \pm 0.01-\mathrm{mL}$ pipette, and samples were left for the EHT in the multifactorial design. The enzymatic lactose hydrolysis and the fermentation were performed in a water bath
(Memmert GmbH + Co. KG, Schwabach, Germany) at $37 \pm 0.1^{\circ} \mathrm{C}$. After the EHT, the fermentation was begun by adding the yogurt culture (Fermovac 1000 S7, a concentrated deep-frozen culture for bulk starter production on VIS-START media; Danisco A/S, Copenhagen, Denmark) with a graduated cylinder and the HN001 culture (Fonterra Research Centre, Palmerston North, New Zealand) with a sterile $1 \pm 0.01-\mathrm{mL}$ pipette. A sample of each assay was taken to determine the initial HN001 count $\left(\mathrm{R}_{1}\right)$.

The incubation ended when the $\mathrm{pH}$ reached 4.60, monitored using a calibrated $\mathrm{pH}$ meter (Hanna Instruments, Ann Arbor, MI). The yogurts were cooled to $15^{\circ} \mathrm{C}$, and samples were taken to determine the afterfermentation HN001 count $\left(\mathrm{R}_{2}\right)$ and lactose content $\left(\mathrm{L}_{2}\right)$. The yogurt was bottled and stored at $5^{\circ} \mathrm{C}$. After $24 \mathrm{~h}$ of standing, sensory quality was evaluated.

For the shelf-life study, $6,000 \mathrm{~kg}$ of yogurt was prepared at industrial scale per the established optimized conditions and packaged in 175-mL high-impact polystyrene bottles that were sealed with polyester paper.

Table 2. List and quantities of ingredients used in the formulation of

\begin{tabular}{|c|c|}
\hline Ingredient & Quantity (g/100 g) \\
\hline \multicolumn{2}{|l|}{ Basic mix } \\
\hline Milk, $3.1 \%$ fat & 831.27 \\
\hline Dry milk, $0 \%$ fat & 35.27 \\
\hline Sucrose & 106.80 \\
\hline Gelatin 250 Bloom & 2.40 \\
\hline Potassium sorbate & 0.05 \\
\hline$\beta$-galactosidase ${ }^{2}$ & According to assay \\
\hline \multicolumn{2}{|l|}{ Culture } \\
\hline Fermovac $1000 \mathrm{~S}^{3}$ & 20.00 \\
\hline Lactobacillus rhamnosus $\mathrm{HN} 01^{4}$ & 0.025 \\
\hline
\end{tabular}
the yogurts for the optimization and shelf-life studies ${ }^{1}$

${ }^{1}$ The ingredients in the basic mix and the cultures were constant in all experiments. In the optimization study, the commercial $\beta$-galactosidase Maxilact LX5000 (DSM, Heerlen, the Netherlands) varied according to the required concentration for each assay in the $2^{2}+\alpha$ experimental model, where $\alpha=1.4147$. In the shelf-life study, the optimum concentration of Maxilact LX5000 was set to $0.0182 \mathrm{~g} / 100 \mathrm{~g}$, corresponding to an optimized 910 neutral lactase units (NLU)/kg.

${ }^{2}$ Maxilact LX5000: 5,000 NLU/g.

${ }^{3}$ Indirect strain (Danisco A/S, Copenhagen, Denmark).

${ }^{4}$ Direct strain (Fonterra Research Centre, Palmerston North, New Zealand). 


\section{Lactose}

Samples for lactose measurements were stored in sterile test tubes at $-25^{\circ} \mathrm{C}$ until analysis. The Association of Official Analytical Chemists method no. 984.15 (Kleyn and Trout, 1984; AOAC, 1990) was followed, using an enzymatic kit, to measure the lactose/Dglucose content in the samples (Boehringer-Mannheim GmbH, Mannheim, Germany). An ATI Unicam UV/ Vis spectrophotometer (ATI Unicam Ltd., Cambridge, UK) was used to measure the stoichiometric concentration of reduced nicotinamide adenine dinucleotide $(\mathrm{NADH})$ that formed during the enzymatic hydrolysis of lactose at $340 \mathrm{~nm}$.

\section{Lactobacillus rhamnosus HN001}

The cultures of HN001 were grown routinely at $37^{\circ} \mathrm{C}$ for $72 \mathrm{~h}$ in de Man, Rogosa, and Sharpe (MRS) agar (Merck KGaA, Darmstadt, Germany; de Man et al., 1960).

\section{Sensory Evaluation}

Fifteen trained sensory assessors evaluated the yogurt samples at the research and development facilities of Soprole SA (Santiago, Chile). The sensory quality of the yogurts was assessed per the Karlsruhe test (Gutschmidt, 1951; Paulus et al., 1969), adapted to the yogurt profile (Domper, 1997). This test scores the quality of the yogurt as follows:

I. Typical: $9=$ excellent; $8=$ very good; and $7=$ good;

II. Tolerable: $6=$ satisfactory; $5=$ regular; and $4=$ sufficient;

III. Undesirable: $3=$ deficient; $2=$ bad; and $1=$ very bad.

Six quality parameters were assessed per these criteria. The overall quality was measured as

$$
\begin{gathered}
\text { Overall quality }=0.10 \text { color }+0.20 \text { appearance } \\
+0.10 \text { aroma }+0.25 \text { flavor }+0.20 \text { texture } \\
+0.15 \text { residual flavor. }
\end{gathered}
$$

In this study, the minimum score for acceptable overall quality of the yogurt was 5 , per the Karlsruhe scale.

\section{Shelf Life}

An accelerated shelf-life study was conducted at 3 temperatures (Labuza, 1982; Labuza and Schmidl,
1985). The yogurt samples were stored at $9 \pm 1^{\circ} \mathrm{C}$ in an industrial warehouse (Soprole SA) and at $25 \pm 1^{\circ} \mathrm{C}$ and $32 \pm 1^{\circ} \mathrm{C}$ in incubators (Memmert $\mathrm{GmbH}+\mathrm{Co} . \mathrm{KG}$ ) for 40,20 , and $5 \mathrm{~d}$, respectively. During these periods, $\mathrm{pH}$, lactose, HN001, and sensory quality were measured. In addition, mold, yeast, and Enterobacteriaceae were detected routinely for compliance (Doyle and Beuchat, 2007). All parameters followed a first-order reaction (Labuza, 1982), represented by the following equation:

$$
\mathrm{Ae}=\mathrm{A}_{0} \mathrm{e}^{k \theta},
$$

where $\mathrm{Ae}$ is the value of $\mathrm{A}$, the dependent variable, at the end of the shelf life, $\mathrm{A}_{0}$ is the initial value of the dependent variable, $k$ is the kinetic constant at the experimental temperature, and $\theta$ is the shelf life in days (Labuza, 1982).

Because the 3 test temperatures were constant (Labuza and Schmidl, 1985), the kinetic constant $k$ obeys the empirical relation of Arrhenius:

$$
k=A \mathrm{e}^{-\mathrm{Ea} / \mathrm{RT}},
$$

which is solved as $\operatorname{Ln} k=\operatorname{Ln} A-\mathrm{Ea} / \mathrm{RT}$, where $k$ is the constant at any given temperature T, $A$ is a pre-exponential constant, Ea is the activation energy (in $\mathrm{KJ} / \mathrm{mol}$ ), $\mathrm{R}$ is the gas constant (in $\mathrm{J} / \mathrm{mol} \cdot \mathrm{K}$ ), and $\mathrm{T}$ is the temperature in Kelvin (Labuza and Schmidl, 1985). Arrhenius coefficients were obtained by plotting Ln $k$ versus the inverse of the 3 storage temperatures in Kelvin.

\section{Statistical Analysis}

The polynomials that were derived from the multifactorial design for optimization were obtained by multiple regression analysis of each dependent variable using Statgraphics Plus 2.0 software (StatPoint Technologies Inc., Warrenton, VA). The coefficients were considered significant at $P<0.1$ and $P<0.05$. Each polynomial was assumed to be valid at $\mathrm{R}^{2}>70 \%$. Surface responses were drawn using Statgraphics Plus 2.0 software. In addition, correlations between parameters were calculated and considered relevant when the Pearson coefficients were $>0.7$ and $<-0.7$ at $P<0.05$.

Once the polynomials of the dependent variables were obtained, the concentration of $\beta \mathrm{G}$ and the EHT were optimized as a function of overall quality, $\mathrm{L}_{2}$, and $\mathrm{R}_{2}$ using Microsoft Excel software (Microsoft Corp., Redmond, WA). Then, a theoretical optimum value was determined for each dependent variable. To analyze the results from the shelf-life study, kinetic and Arrhenius 
Table 3. Coefficients and $\mathrm{R}^{2}$ values for the type 1 polynomials generated for each dependent variable after multiple regression analysis of the results of the 10 experiments derived from the $2^{2}+\alpha$ model, where $\alpha=1.4147^{1}$

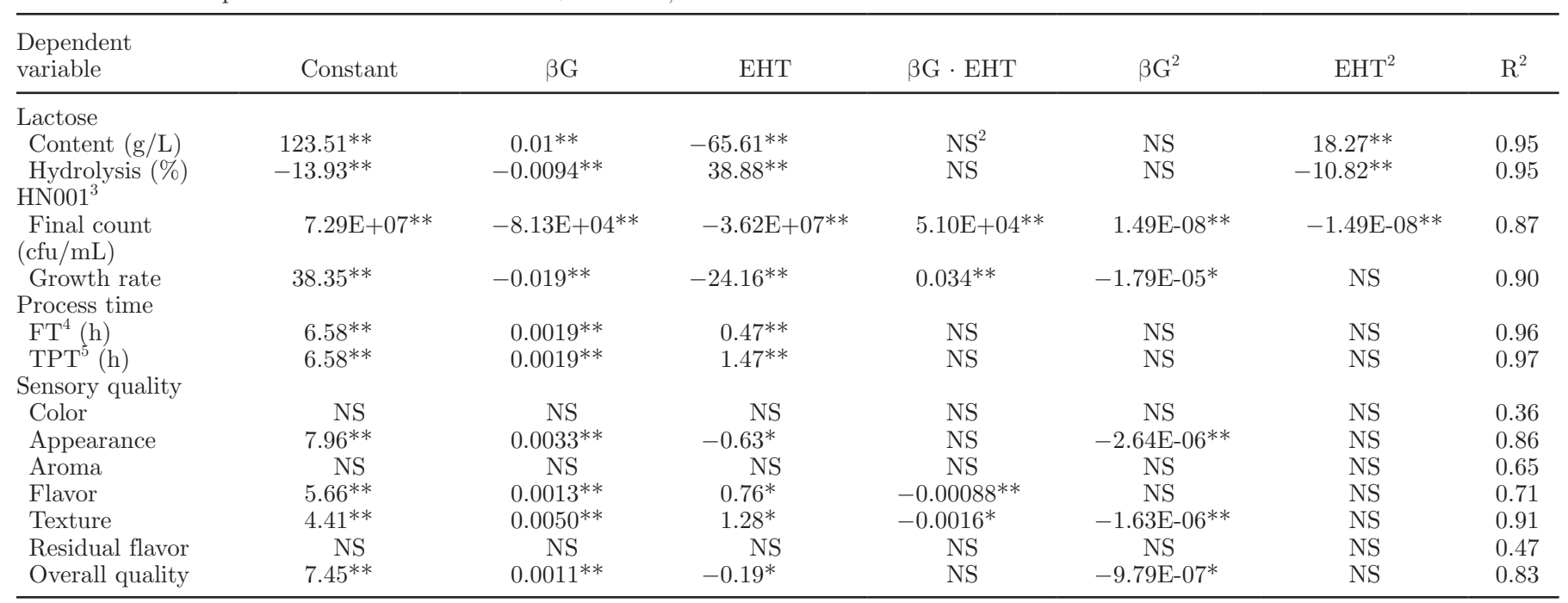

${ }^{1}$ Polynomials are expressed as dependent variable $=\mathrm{K}_{0}+\mathrm{K}_{1} \cdot \beta$-galactosidase $[\beta \mathrm{G}$; neutral lactase units $(\mathrm{NLU}) / \mathrm{kg}]+\mathrm{K}_{2} \cdot$ enzymatic hydrolysis time $(\mathrm{EHT} ; \mathrm{h})+\mathrm{K}_{3} \cdot \beta \mathrm{G}(\mathrm{NLU} / \mathrm{kg}) \cdot \mathrm{EHT}(\mathrm{h})+\mathrm{K}_{4} \cdot \beta \mathrm{G}(\mathrm{NLU} / \mathrm{kg})^{2}+\mathrm{K}_{5} \cdot \mathrm{EHT}(\mathrm{h})^{2}$, where $\mathrm{K}$ represents the coefficients of the polynomial.

${ }^{2} \mathrm{NS}=$ nonsignificant at $P>0.10$.

${ }^{3}$ Lactobacillus rhamnosus HN001 (Fonterra Research Centre, Palmerston North, New Zealand).

${ }^{4}$ Fermentation time.

${ }^{5}$ Total process time.

$* P \leq 0.10 ; * * P \leq 0.05$.

equations were calculated by simple regression using Statgraphics Plus 2.0 software.

\section{RESULTS}

\section{Polynomials}

The multifactorial design selected described the hydrolysis of lactose, the growth of HN001, the fermentation time, and the sensory quality of the yogurt as dependent variables of $\beta \mathrm{G}$ concentration and EHT (Tables 3 and 4).

The $\mathrm{L}_{2}$ ranged between 1.76 and $18.67 \mathrm{~g} / \mathrm{L}$, which represent a level of hydrolysis between $97.0 \%$ and $80.8 \%$, respectively; the $\mathrm{L}_{1}$ was $59.27 \mathrm{~g} / \mathrm{L}$ (Table 2). The 2 polynomials for lactose content and hydrolysis were explained by the 2 independent factors, as well as the quadratic factor of EHT (Table 3). The principal factor that influenced the level of hydrolysis was $\beta \mathrm{G}$ concentration (Table 4). The surface response of the lactose content is presented in Figure 2.

The $\mathrm{R}_{2}$ ranged between $6 \times 10^{6}$ and $6 \times 10^{7} \mathrm{cfu} /$ $\mathrm{mL}$, which represented a 3.3 - to 40 -fold increase during the fermentation, respectively, corresponding to an $\mathrm{R}_{1}$ between $1.8 \times 10^{6}$ and $1.5 \times 10^{6} \mathrm{cfu} / \mathrm{mL}$ on addition of $0.025 \mathrm{~g}$ of culture per $100 \mathrm{~g}$ of basic mix in the respective experiments (Table 2). The polynomial for the $R_{2}$ in the yogurt was explained by the $\beta G$ concentration and EHT, their interaction, and quadratic factors (Table 3). The growth rate of HN001 correlated positively with the level of lactose hydrolysis (Table 4). The surface response of the HN001 count is shown in Figure 3.

The FT in the assays ranged between 8.2 and $10.8 \mathrm{~h}$, whereas the TPT ranged between 9.7 and $13.0 \mathrm{~h}$. The polynomial of the FT and, consequently, the polynomial of the TPT were also explained by the 2 independent factors (Table 3 ). The TPT correlated positively with $\beta G$ concentration, the level of lactose hydrolysis, and the $R_{2}$ in the yogurt (Table 4). The surface response of the FT is displayed in Figure 4.

Regarding the sensory parameters, the polynomials explained the appearance, flavor, texture, and consequently, the overall quality of the yogurt (Table 3). However, they did not explain the color, aroma, or residual flavor.

The overall sensory quality of the samples ranged between 6.98 and 7.40 on the Karlsruhe scale. The overall quality correlated negatively with $\beta G$ concentration, the $\mathrm{R}_{2}$, and the fermentation and TPT (Table 4). The surface response of the overall quality is shown in Figure 5.

In summary, HN001 correlated positively with the level of lactose hydrolysis. However, the low lactose 
OPTIMIZATION AND SHELF LIFE OF A LOW-LACTOSE YOGURT

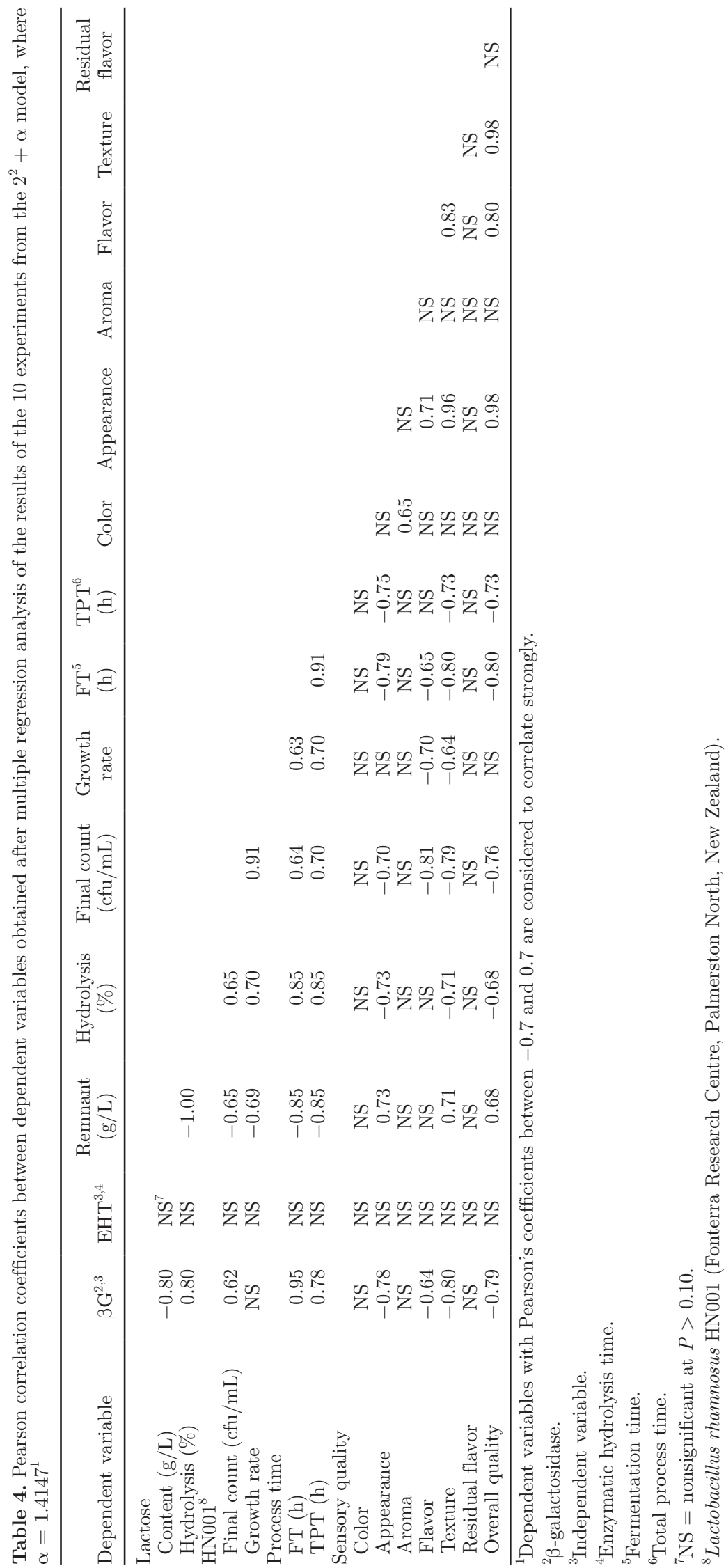




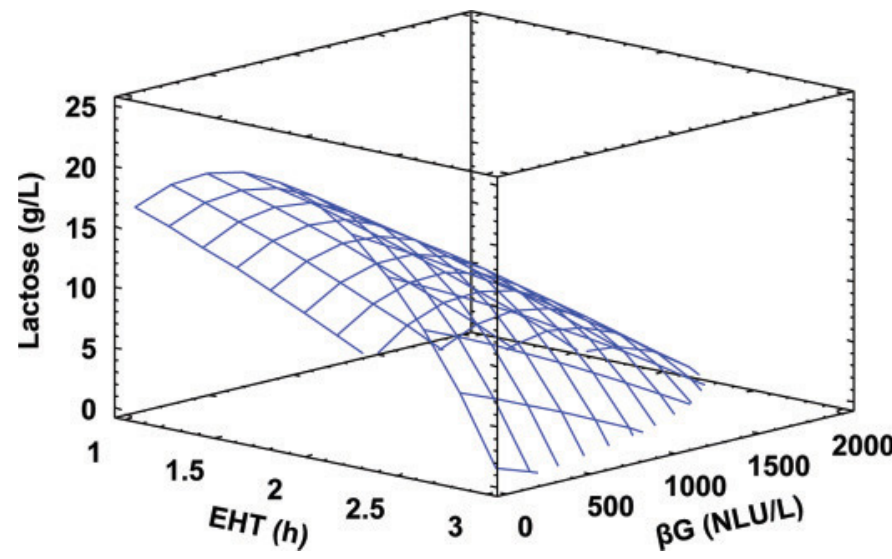

Figure 2. Surface response for lactose content, corresponding to the type 1 polynomial obtained from the analysis of the $2^{2}+\alpha$ model where $\alpha=1.4147$. Lactose $(\mathrm{g} / \mathrm{L})=153.51+0.01 \beta$-galactosidase $[\beta \mathrm{G}$; neutral lactase units $(\mathrm{NLU}) / \mathrm{kg}]$ - 65.61 enzymatic hydrolysis time $(\mathrm{EHT} ; \mathrm{h})+18.27 \mathrm{EHT}(\mathrm{h})^{2}$. Color version available in the online PDF.

content and high HN001 count in the yogurt lowered its overall quality and increased the fermentation and process times.

\section{Optimized Conditions}

Polynomials were used to optimize the $\beta \mathrm{G}$ concentration and EHT to obtain a yogurt with at least $1 \times$ $10^{7} \mathrm{cfu}$ of HN001/mL, a minimum of $10 \mathrm{~g}$ of lactose remnants/L, and a minimum overall quality of 7 on the Karlsruhe scale. This analysis yielded theoretical

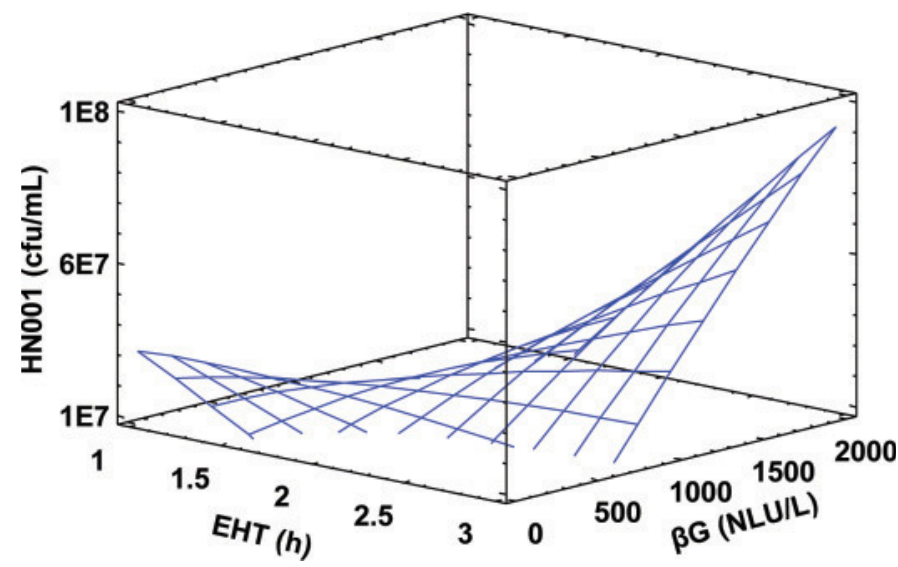

Figure 3. Surface response for Lactobacillus rhamnosus HN001 (HN001) count, corresponding to the type 1 polynomial obtained from the analysis of the $2^{2}+\alpha$ model, where $\alpha=1.4147$. Lactobacillus rhamnosus HN001 $(\mathrm{cfu} / \mathrm{mL})=7.29 \times 10^{7}-8.13 \times 10^{4} \beta$-galactosidase $[\beta \mathrm{G}$; neutral lactase units $(\mathrm{NLU}) / \mathrm{kg}]-3.62 \times 10^{7}$ enzymatic hydrolysis time $(\mathrm{EHT} ; \mathrm{h})+5.10 \times 10^{4} \beta \mathrm{G}(\mathrm{NLU} / \mathrm{kg}) \cdot \mathrm{EHT}(\mathrm{h})+1.49 \times$ $10^{-8} \beta \mathrm{G}(\mathrm{NLU} / \mathrm{kg})^{2}-1.49 \times 10^{-8} \mathrm{EHT}(\mathrm{h})^{2}$. Color version available in the online PDF.

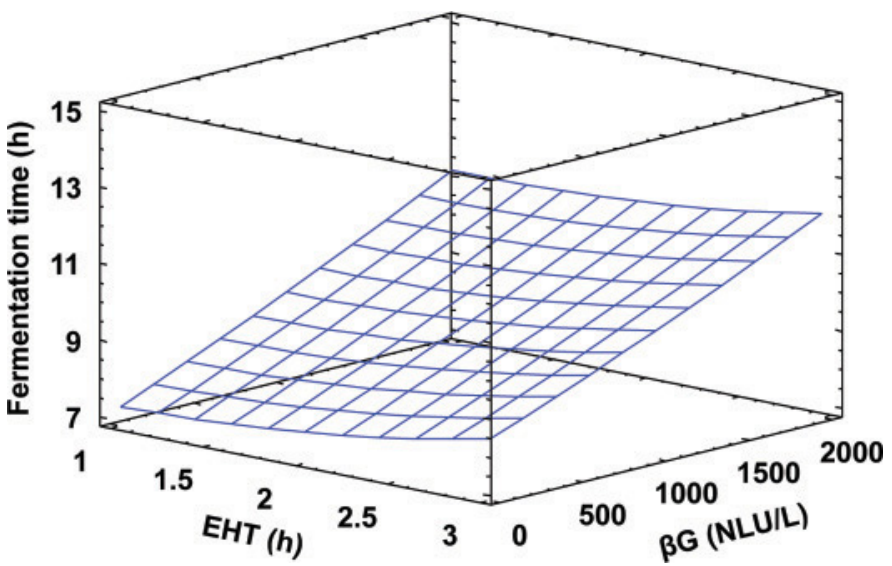

Figure 4. Surface response for fermentation time, corresponding to the type 1 polynomial obtained from the analysis of the $2^{2}+\alpha$ model, where $\alpha=1.4147$. Fermentation time $(\mathrm{h})=6.58+0.0019$ $\beta$-galactosidase $[\beta \mathrm{G}$; neutral lactase units $(\mathrm{NLU}) / \mathrm{kg}]+0.47$ enzymatic hydrolysis time (EHT; h). Color version available in the online PDF.

optimum values of 910 neutral lactase units of $\beta \mathrm{G} / \mathrm{kg}$ and an EHT of $2.3 \mathrm{~h}$.

The theoretical values for all independent variables and their $95 \%$ confidence intervals for the optimized $\beta \mathrm{G}$ concentrations and EHT are shown in Table 5. This table also shows the results for the independent variables when an experimental assay, at an industrial scale of $6,000 \mathrm{~kg}$, was performed at the optimized conditions. In this assay, all dependent variable values fell within the range of theoretical estimated confidence intervals.

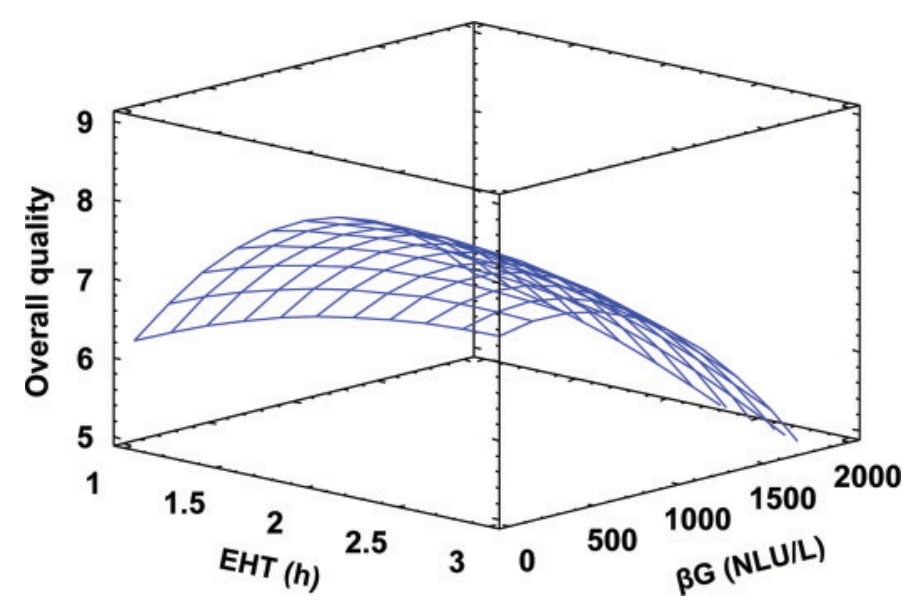

Figure 5. Surface response for overall sensory quality, corresponding to the type 1 polynomial obtained from the analysis of the $2^{2}+$ $\alpha$ model, where $\alpha=1.4147$. Overall sensory quality $=7.45+0.0011$ $\beta$-galactosidase $[\beta \mathrm{G}$; neutral lactase units $(\mathrm{NLU}) / \mathrm{kg}]-0.19$ enzymatic hydrolysis time $(\mathrm{EHT} ; \mathrm{h})-9.79 \times 10^{-7} \beta \mathrm{G}(\mathrm{NLU} / \mathrm{kg})^{2}$. Color version available in the online PDF. 
Table 5. Theoretical and experimental values for the dependent variables lactose, Lactobacillus rhamnosus HN001, process time, and sensory parameters obtained at the optimal $\beta$-galactosidase concentration (910 neutral lactase units $/ \mathrm{kg})$ and enzymatic hydrolysis time $(2.3 \mathrm{~h})^{1}$

\begin{tabular}{|c|c|c|c|c|}
\hline Dependent variable & Estimated & Inferior $95 \%$ & Superior $95 \%$ & Experimental \\
\hline \multicolumn{5}{|l|}{ Lactose } \\
\hline Content (g/L) & 9.61 & 7.98 & 11.22 & 9.22 \\
\hline Hydrolysis (\%) & 83.69 & 81.05 & 86.52 & 84.64 \\
\hline \multicolumn{5}{|l|}{$\mathrm{HN} 001^{2}$} \\
\hline Final count $(\mathrm{cfu} / \mathrm{mL})$ & $2.23 \mathrm{E}+07$ & $1.57 \mathrm{E}+07$ & $2.88 \mathrm{E}+07$ & $4.30 \mathrm{E}+07$ \\
\hline Growth rate & 21.60 & 15.59 & 27.60 & 27.92 \\
\hline \multicolumn{5}{|l|}{ Process time } \\
\hline $\mathrm{FT}^{3}(\mathrm{~h})$ & 9.44 & 9.23 & 9.64 & 9.87 \\
\hline $\mathrm{TPT}^{4}(\mathrm{~h})$ & 11.74 & 11.53 & 11.93 & 12.17 \\
\hline \multicolumn{5}{|l|}{ Sensory quality } \\
\hline Color & - & - & - & 8.13 \\
\hline Appearance & 7.34 & 6.67 & 7.99 & 7.88 \\
\hline Aroma & - & - & - & 6.25 \\
\hline Flavor & 6.83 & 6.64 & 7.01 & 7.00 \\
\hline Texture & 7.19 & 6.74 & 7.64 & 7.63 \\
\hline Residual flavor & - & - & - & 6.25 \\
\hline Overall quality & 7.28 & 6.89 & 7.67 & 7.23 \\
\hline
\end{tabular}

${ }^{1}$ The theoretical values were estimated using the type 1 polynomials from the $2^{2}+\alpha$ model (where $\alpha=1.4147$ ) to obtain yogurt with $>1 \times 10^{7} \mathrm{cfu}$ of $\mathrm{HN} 001 / \mathrm{mL},<10 \mathrm{~g}$ of lactose/L, and a minimum overall sensory quality of 7 on the Karlsruhe scale. The experimental values were obtained after analyzing an industrial batch of 6,000 $\mathrm{kg}$ produced at the optimized conditions.

${ }^{2}$ Lactobacillus rhamnosus HN001 (Fonterra Research Centre, Palmerston North, New Zealand).

${ }^{3}$ Fermentation time.

${ }^{4}$ Total process time.

Thus, the optimum conditions for $\beta G$ concentration and EHT were validated.

\section{Shelf Life}

Samples from the 6,000-kg industrial assay were stored at the 3 temperatures from the shelf life study, and dependent variables were examined.

The kinetic equations for the lactose content, HN001 count, $\mathrm{pH}$, and overall quality at the 3 temperatures are reported in Table 6. All dependent variables followed a first-order reaction. Representative results at $9^{\circ} \mathrm{C}$, the normal storage temperature of yogurt at the industrial scale, are shown in Figures $6 \mathrm{~A}, 7 \mathrm{~A}, 8 \mathrm{~A}$, and $9 \mathrm{~A}$, respectively. The yogurt had a shelf life that exceeded $30 \mathrm{~d}$ - the recommended commercial time of consumption - for all parameters in the tests at $9^{\circ} \mathrm{C}$. The hydrolysis of lactose and HN001 growth continued during the storage of the yogurt. The $\mathrm{pH}$ and overall quality decreased during storage.

The kinetic constants allowed us to calculate empirical Arrhenius equations for the dependent variables, as shown in Table 7; all equations gave good $\mathrm{R}^{2}$ correlations, indicating their suitability for extrapolating shelf life conditions for the dependent variables in the range of temperatures that were tested: $9^{\circ} \mathrm{C}, 25^{\circ} \mathrm{C}$, and $32^{\circ} \mathrm{C}$. Figures $6 \mathrm{~B}, 7 \mathrm{~B}, 8 \mathrm{~B}$, and $9 \mathrm{~B}$ show the Arrhenius equations for lactose content, HN001 count, pH, and overall sensory quality, respectively.
Table 6. Kinetic coefficients and $\mathrm{R}^{2}$ values obtained in the shelf-life study for lactose, Lactobacillus rhamnosus HN001, pH, and overall sensory quality ${ }^{1}$

\begin{tabular}{llll}
\hline $\begin{array}{l}\text { Dependent } \\
\text { variable }\end{array}$ & $A_{0}{ }^{2}$ & $k^{3}$ & $\mathrm{R}^{2}$ \\
\hline $\begin{array}{l}\text { Lactose }(\mathrm{g} / \mathrm{L}) \\
9^{\circ} \mathrm{C}\end{array}$ & 8.85 & -0.0054 & 0.85 \\
$25^{\circ} \mathrm{C}$ & 9.15 & -0.0318 & 0.90 \\
$32^{\circ} \mathrm{C}$ & 8.81 & -0.0822 & 0.97 \\
$\mathrm{HN} 001^{4}(\mathrm{cfu} / \mathrm{mL})$ & & & \\
$9^{\circ} \mathrm{C}$ & $4.0 \mathrm{E}+7$ & 0.0198 & 0.76 \\
$25^{\circ} \mathrm{C}$ & $3.0 \mathrm{E}+7$ & 0.1807 & 0.86 \\
$32^{\circ} \mathrm{C}$ & $4.0 \mathrm{E}+7$ & 0.4417 & 0.99 \\
$\mathrm{pH}$ & & & \\
$9^{\circ} \mathrm{C}$ & 4.22 & -0.0005 & 0.75 \\
$25^{\circ} \mathrm{C}$ & 4.20 & -0.0085 & 0.91 \\
$32^{\circ} \mathrm{C}$ & 4.25 & -0.0319 & 0.97 \\
$\mathrm{Overall} \mathrm{quality}$ & & & \\
$9^{\circ} \mathrm{C}$ & 6.79 & -0.0081 & 0.96 \\
$25^{\circ} \mathrm{C}$ & 6.58 & -0.0430 & 0.94 \\
$32^{\circ} \mathrm{C}$ & 6.84 & -0.1228 & 0.99 \\
\hline
\end{tabular}

${ }^{1}$ The accelerated shelf-life studies were performed at 3 temperatures $\left(9^{\circ} \mathrm{C}, 25^{\circ} \mathrm{C}\right.$, and $\left.32^{\circ} \mathrm{C}\right)$ and ended when the overall quality reached 5 on the Karlsruhe scale. All parameters followed a first-order reaction at each temperature, expressed as $\mathrm{Ae}=\mathrm{A}_{0} \mathrm{e}^{k \theta}$, where Ae is the value of $\mathrm{A}$ at the end of the shelf life, $\mathrm{A}_{0}$ is the initial value of quality, $k$ is the kinetic constant, and $\theta$ is the shelf life in days.

${ }^{2}$ Initial condition.

${ }^{3}$ Kinetic constant.

${ }^{4}$ Lactobacillus rhamnosus HN001 (Fonterra Research Centre, Palmerston North, New Zealand). 


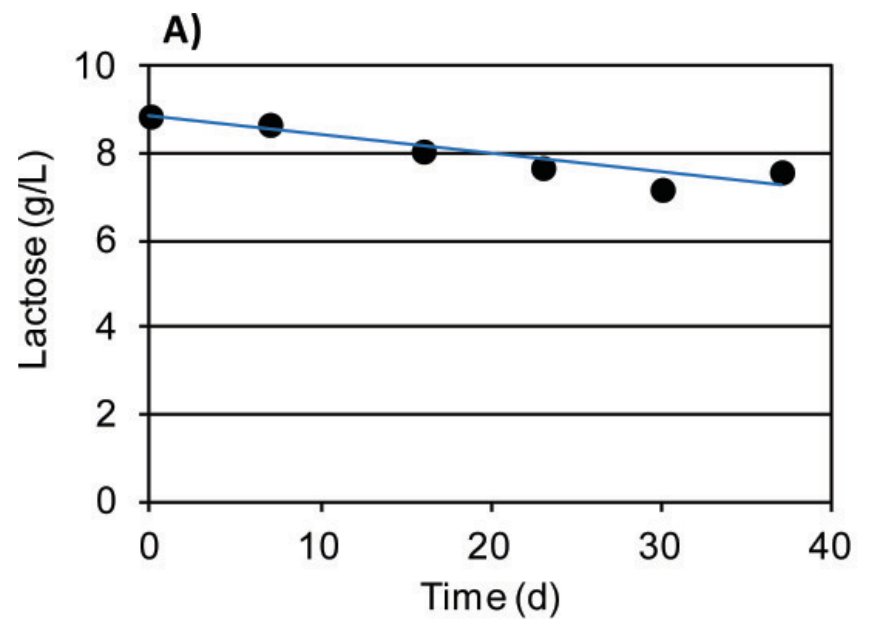

B)

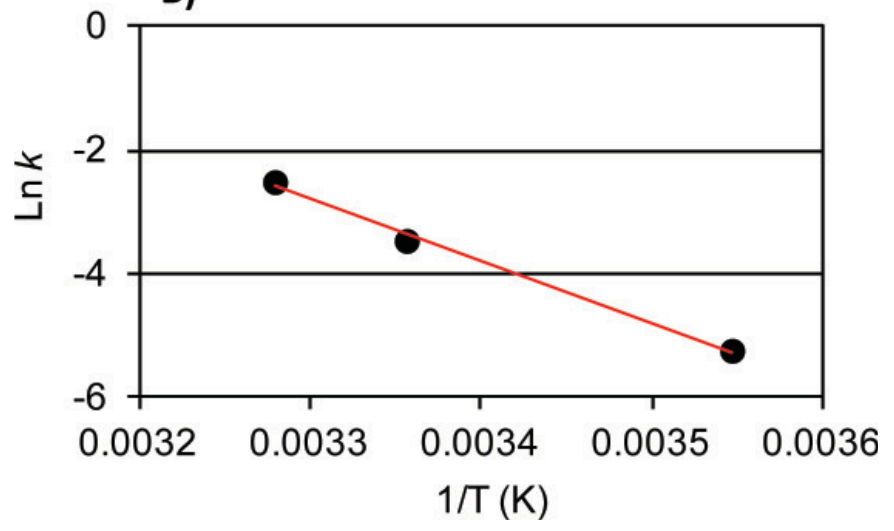

Figure 6. Shelf life for lactose content. Panel A represents the kinetics at $9^{\circ} \mathrm{C}$ (industrial warehouse temperature), allowing us to estimate the content of lactose at any given time: Lactose $(\mathrm{g} / \mathrm{L})_{9^{\circ} \mathrm{C}}=$ $8.85 \mathrm{e}^{-0.0054 \mathrm{~d}}$. Panel B represents the Arrhenius equation in the range of the temperatures tested in the accelerated shelf life study $\left(9^{\circ} \mathrm{C}\right.$, $25^{\circ} \mathrm{C}$, and $32^{\circ} \mathrm{C}$ ), allowing us to calculate the kinetic $(k)$ constant at any given temperature $(\mathrm{T})$ and subsequently estimate lactose content at any given storage temperature: $\operatorname{Ln} k_{\text {Lactose }(\mathrm{g} / \mathrm{L})}=30.27-10,017$. $1 / \mathrm{T}($ Kelvin, K). Color version available in the online PDF,

\section{DISCUSSION}

The multifactorial design, $2^{2}+\alpha$, where $\alpha=1.4147$, generated polynomials that explained the dependent variables with high sensitivity. Notably, this design successfully modeled variables on an arithmetic scale, such as lactose content, sensory quality, and process times, as well as the growth of HN001, whose values oscillated 1 logarithmic scale between experiments. Previous reports have optimized metabolites in yogurt using surface response methods, such as hydrolysis of lactose, lactic acid production, and processing time (Toba et al., 1986; Téllez-Luis et al., 2003). Similar experiences using multifactorial designs have been described for Lb. delbrueckii ssp. bulgaricus ST56 and Streptococcus thermophilus DN21 in yogurt, wherein the analysis of response surfaces allowed the operational conditions that were needed to optimize the performance of the strains to be identified (Torriani et al., 1996). In our study, based on the multifactorial design that we chose, we established a positive correlation between the hydrolysis of lactose and the growth of HN001, which were inversely associated with overall quality in the range of independent variables that we examined.

When a typical yogurt is processed, approximately $30 \%$ of the lactose is hydrolyzed, yielding approximately $40 \mathrm{~g}$ of lactose/L of product (Toba et al., 1983), a concentration that enhances the digestion of lactose in lactase-deficient individuals (Savaiano et al., 1984). The optimized process that we have reported effected a lactose hydrolysis rate of more than $80 \%$ and yielded less than $10 \mathrm{~g}$ of lactose/L in the yogurt. In adults with lactose intolerance, symptoms occur after consumption
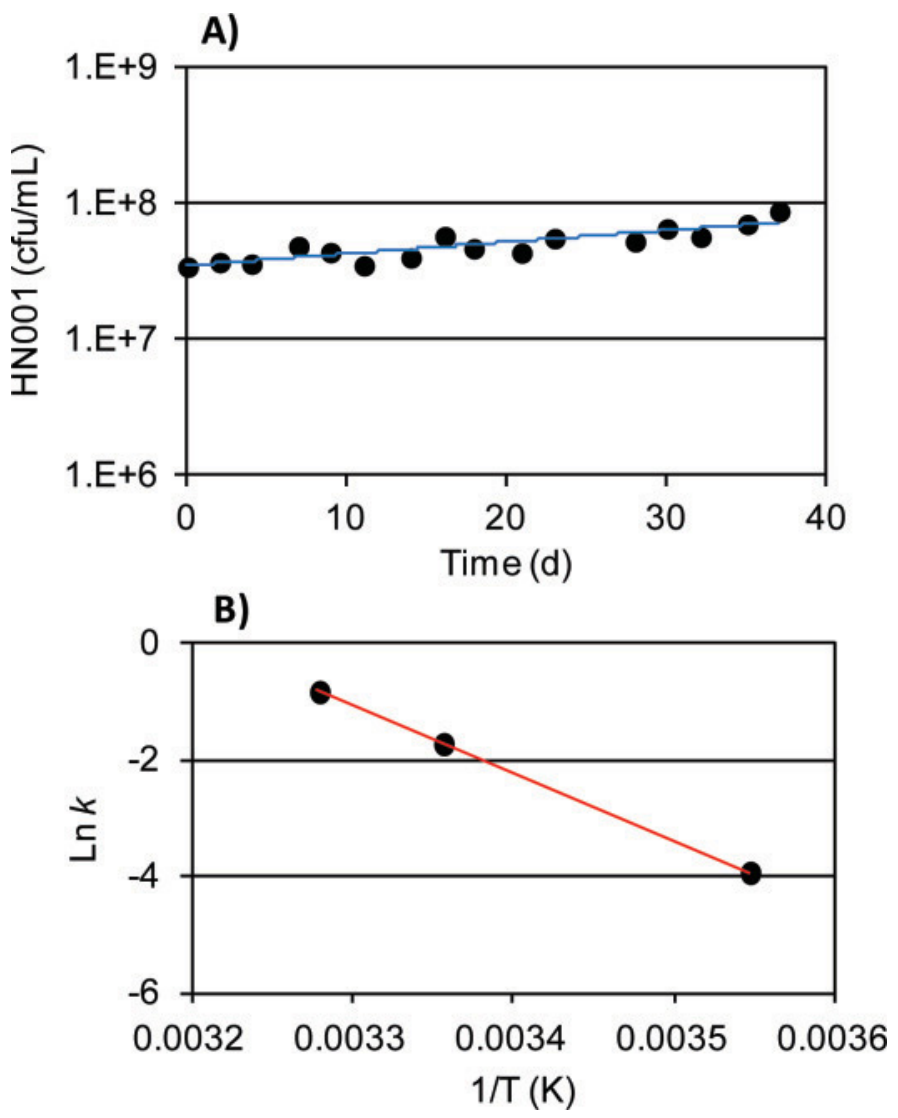

Figure 7. Shelf life for Lactobacillus rhamnosus HN001 count. Panel A represents the kinetics at $9^{\circ} \mathrm{C}$ (industrial warehouse temperature), allowing us to estimate the count of HN001 at any given time: HN001 $(\mathrm{cfu} / \mathrm{mL})_{9^{\circ} \mathrm{C}}=4 \times 10^{7} \mathrm{e}^{0.0198 \mathrm{~d}}$. Panel B represents the Arrhenius equation in the range of temperatures tested in the accelerated shelf life study $\left(9^{\circ} \mathrm{C}, 25^{\circ} \mathrm{C}\right.$, and $\left.32^{\circ} \mathrm{C}\right)$, allowing us to calculate the kinetic (k) constant at any given temperature $(\mathrm{T})$ and subsequently estimate the HN001 count at any given storage temperature: Ln $k_{\mathrm{HN} 001(\mathrm{cfu} / \mathrm{mL})}=$ $37.25-11,612 \cdot 1 / \mathrm{T}($ Kelvin, K). Color version available in the online PDF. 


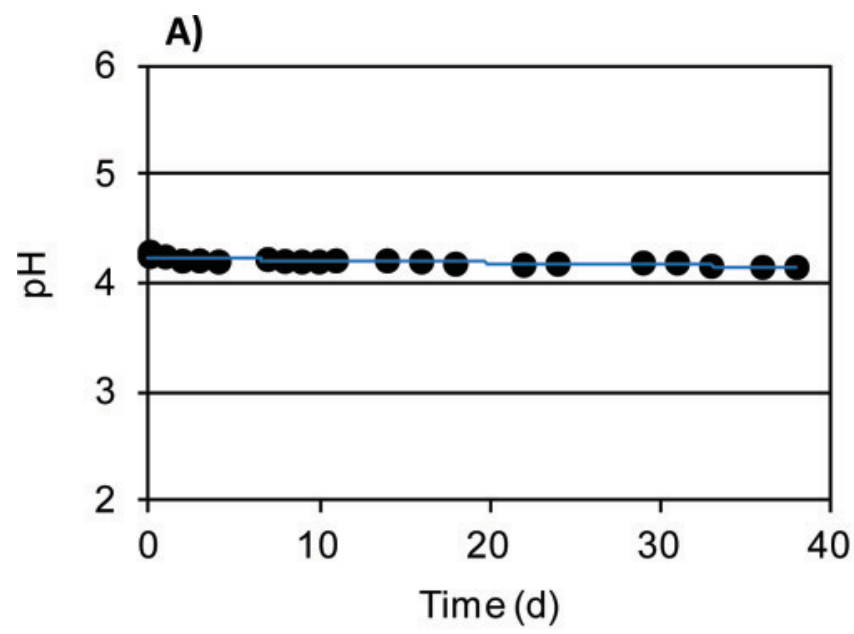

B)

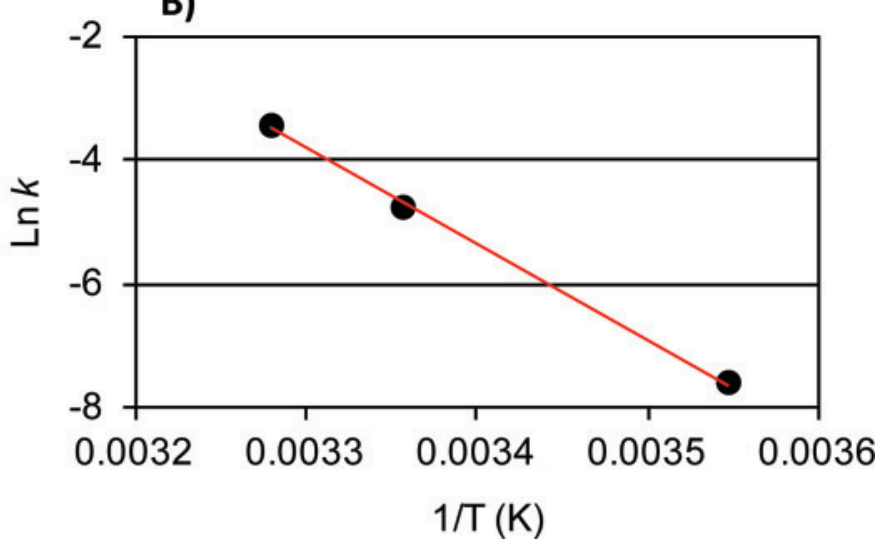

Figure 8. Shelf life for $\mathrm{pH}$. Panel A represents the kinetic at $9^{\circ} \mathrm{C}$ (industrial warehouse temperature), allowing us to estimate the $\mathrm{pH}$ at any given time: $\mathrm{pH}_{9^{\circ} \mathrm{C}}=4.22 \mathrm{e}^{-0.0005 \mathrm{~d}}$. Panel $\mathrm{B}$ represents the Arrhenius equation in the range of temperatures tested in the accelerated shelf life study $\left(9^{\circ} \mathrm{C}, 25^{\circ} \mathrm{C}\right.$, and $\left.32^{\circ} \mathrm{C}\right)$, allowing us to calculate the kinetic (k) constant at any given temperature $(\mathrm{T})$ and subsequently estimate the $\mathrm{pH}$ at any given storage temperature: $\mathrm{Ln} k_{\mathrm{pH}}=47.04-15,415$. $1 / \mathrm{T}($ Kelvin, K). Color version available in the online PDF.

of $2 \mathrm{~g}$ of lactose, and up to $6 \mathrm{~g}$ per serving can be tolerated (Hertzler et al., 1996).

Many factors affect the severity of symptoms after ingestion of lactose, including ethnicity and age - older individuals are more susceptible (Lloyd and Olsen, 1995; Swagerty et al., 2002). Thus, the concentration of lactose per serving of the yogurt that we optimized, equivalent to approximately $1.75 \mathrm{~g}$ in a $175-\mathrm{mL}$ serving, is suitable for lactose-intolerant individuals. Moreover, the hydrolysis of lactose continued during the shelf life of the optimized yogurt, further decreasing its lactose content.

Conversely, other groups have reported a significant decrease in $\beta \mathrm{G}$ activity during the storage of a standard yogurt (Galvão et al., 1995). We attribute the additional hydrolysis of lactose during storage of the optimized yogurt to the availability of $\beta \mathrm{G}$ in the media, as a result of the addition of a commercial enzyme (Maxilact LX5000), which augmented the $\beta G$ that was produced in the yogurt cultures.

Clinical studies have indicated that daily administration of HN001 ameliorates several immune systemrelated conditions (Sheih et al., 2001; Prescott et al., 2008; Wickens et al., 2008). Generally, at least $10^{9}$ cfu of probiotics should be ingested daily to stimulate the immune system (Ouwehand et al., 2002). The supplementation of $6 \times 10^{9} \mathrm{cfu}$ of HN001/d during pregnancy can influence fetal immune parameters and immunomodulatory factors in breast milk (Prescott et al., 2008). Further, dietary consumption of HN001 above $10^{9} \mathrm{cfu} / \mathrm{d}$, in a base of low-fat milk or lactose-

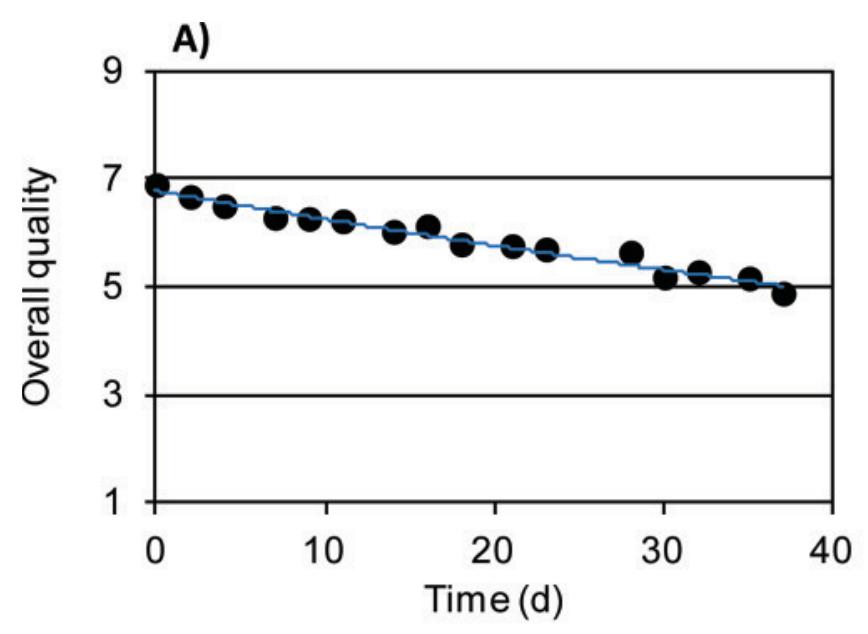

B)

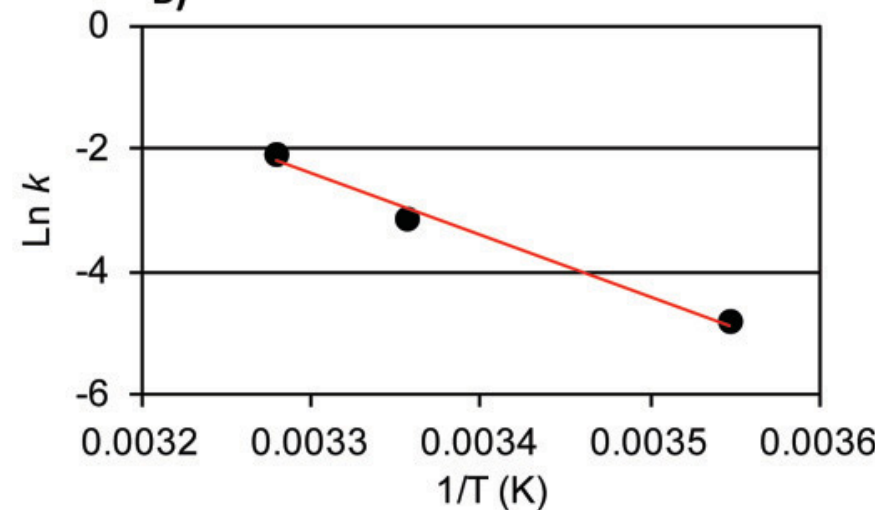

Figure 9. Shelf life for overall sensory quality. Panel A represents the kinetic at $9^{\circ} \mathrm{C}$ (industrial warehouse temperature), allowing us to estimate the overall sensory quality at any given time: Overall sensory quality $_{9^{\circ} \mathrm{C}}=6.79 \mathrm{e}^{-0.0081 \mathrm{~d}}$. Panel $\mathrm{B}$ represents the Arrhenius equation in the range of temperatures tested in the accelerated shelf life study $\left(9^{\circ} \mathrm{C}, 25^{\circ} \mathrm{C}\right.$, and $\left.32^{\circ} \mathrm{C}\right)$, allowing us to calculate the kinetic $(k)$ constant at any given temperature ( $\mathrm{T}$ ) and subsequently to estimate the overall sensory quality at any given storage temperature: Ln $k_{\text {overall sensory quality }}$ $=30.25-9.901 \cdot 1 / \mathrm{T}($ Kelvin, $\mathrm{K})$. Color version available in the online PDF. 
Table 7. Coefficients of the Arrhenius equations and $\mathrm{R}^{2}$ values for lactose, Lactobacillus rhamnosus HN001, pH, and overall sensory quality

\begin{tabular}{lccc}
\hline $\begin{array}{l}\text { Dependent } \\
\text { variable }\end{array}$ & $\mathrm{Ln} A$ & $\mathrm{Ea} / \mathrm{R}^{2}$ & $\mathrm{R}^{2}$ \\
\hline Lactose $(\mathrm{g} / \mathrm{L})_{\mathrm{HN001}}^{3}(\mathrm{cfu} / \mathrm{mL})$ & 30.27 & $-10,017$ & 0.99 \\
$\mathrm{pH}$ & 37.25 & $-11,612$ & 1.00 \\
Overall quality & 47.04 & $-15,415$ & 0.99 \\
\hline
\end{tabular}

${ }^{1}$ The Arrhenius equations allowed us to estimate the shelf life of each variable in the range of the temperature tested in the shelf-life study Because the 3 temperatures in the shelf life study $\left(9^{\circ} \mathrm{C}, 25^{\circ} \mathrm{C}\right.$, and $32^{\circ} \mathrm{C}$ ) were constant, the kinetic constant $k$ obeys the empirical relation $\operatorname{Ln} k=\operatorname{Ln} A-\mathrm{Ea} / \mathrm{RT}$, where $k$ is the constant that depends on temperature, $A$ is a pre-exponential constant, Ea is the activation energy (in $\mathrm{KJ} / \mathrm{mL}$ ), R is the gas constant (in $\mathrm{J} / \mathrm{mol} \cdot \mathrm{K}$ ), and $\mathrm{T}$ is the temperature in Kelvin $(\mathrm{K})$.

${ }^{2}$ Gas constant $(8.3145 \mathrm{~J} / \mathrm{mol} \cdot \mathrm{K})$.

${ }^{3}$ Lactobacillus rhamnosus HN001 (Fonterra Research Centre, Palmerston North, New Zealand).

hydrolyzed low-fat milk, appears to enhance systemic cellular immune responses (Sheih et al., 2001). The daily administration of HNO01 at $6 \times 10^{9} \mathrm{cfu} / \mathrm{d}$ substantially reduces the cumulative prevalence of eczema, by an unknown mechanism (Wickens et al., 2008).

These clinical studies were performed using higher doses than those we deemed to be optimal in the development of our yogurt. Nevertheless, Lb. rhamnosus stimulates the immune system in a dose-dependent manner (Gill and Rutherfurd, 2001; Evrard et al., 2011). Thus, a concentration of HN001 of greater than $1 \times 10^{8} \mathrm{cfu}$ in a serving of $175 \mathrm{~mL}$ of the optimized yogurt can have immune-stimulating benefits.

We noted that the growth of HNO01 depends on the concentration of $\beta \mathrm{G}$ and, consequently, the hydrolysis of lactose, which generates glucose and galactose as byproducts. Lactobacillus rhamnosus HN001 grows better in dairy media that is rich in lactose-derived monosaccharides, preferably in the presence of $\beta G$ (Gopal et al., 2001). This finding might explain the positive correlation between the level of hydrolyzed lactose and the growth of HN001 during the optimization of the yogurt. Moreover, the continuous growth of HN001 during the shelf life of the product might also be related to the activity of $\beta \mathrm{G}$, which might have provided additional substrate during storage.

The normal FT to reach a final $\mathrm{pH}$ of 4.60 in a typical yogurt is approximately 4 to $6 \mathrm{~h}$ at $45^{\circ} \mathrm{C}$ (Chandan, 2006). We expected that the hydrolysis of lactose would lower the FT due to the increase in simple sugars in the media, as reported by O'Leary and Woychik (1976), Nagaraj et al. (2009), and Matijević et al. 2011), but this hypothesis was incorrect. As discussed, the fermentation times varied between 8.2 and $10.8 \mathrm{~h}$. We fermented the mixtures at $37^{\circ} \mathrm{C}$ to favor the hydrolysis of lactose, which might have delayed the FT but cannot explain the long FT in the experiments entirely. The fermentation time correlated with the level of lactose hydrolysis and growth of HN001, perhaps influenced by competition between the typical LAB in the yogurt and the probiotic bacteria HN001.

Depending on the FT, Lb. rhamnosus synthesizes disparate amounts of metabolic products compared with typical yogurt strains (Østlie et al., 2003). In addition, HN001 might have had an advantage over the other 2 bacterial strains due to the hydrolysis of lactose, which provided substrate (Gopal et al., 2001), and the lower temperature of the fermentation in our study, which was optimal for its growth (De Keersmaecker et al., 2006).

The sensory panel that evaluated the typical yogurt comprised well-trained assessors. Thus, we expected that the hydrolysis of lactose would ameliorate the sensory profile of the yogurt, as in other reports, in which fermented and lactose-hydrolyzed dairy products scored better on sensory parameters due to the increase in sweetness, which masked the acidic taste (Nagaraj et al., 2009; Matijević et al., 2011). Yet, the overall sensory quality decreased as the level of lactose hydrolysis rose. Based on comments from the sensory assessors, yogurts that contained a very low lactose content and high HN001 counts were lumpier and differed significantly in viscosity and cohesiveness compared with a typical yogurt, which might explain why the sensory parameters of appearance and texture were altered by the independent variables. Other aspects, such as color and aroma, did not differ from those of a typical yogurt.

As discussed, the hydrolysis of lactose correlated with the growth of HN001 and the FT. We hypothesize that excessive growth of HN001 lowers the sensory quality of yogurt. A report has indicated that high levels of lactobacillus negatively influence the quality of yogurt (Olson and Aryana, 2008), which might explain, in part, why sensory quality decreases with increasing HN001 growth. Nevertheless, the sensory properties of yogurts that are enriched in Lb. rhamnosus have desirable sensory characteristics (Xu et al., 2006) and are comparable with standard yogurts in consumer tests (Hekmat and Reid, 2006). In our study, the optimized conditions allowed us to produce a yogurt that received a score of 7 on the Karlsruhe scale, which is acceptable for commercial use.

In this study, the yogurt was stable during storage with regard to lactose content, HN001 count, and sensory quality. Moreover, the kinetics of the dependent variables that we examined allowed us to calculate Arrhenius equations to extrapolate the shelf life of the yogurts in the range of the temperatures that were studied. 


\section{CONCLUSIONS}

We produced a high-quality yogurt with low lactose content and a suitable HN001 count. The growth of HN001 depended on the hydrolysis of lactose. The FT increased with our novel process. Attention must be paid to ensure a suitable sensory profile when producing a yogurt with optimum levels of lactose hydrolysis and HN001 growth. The yogurt that we have developed is stable during its shelf life.

\section{ACKNOWLEDGMENTS}

Financial support from the University of Chile (Santiago, Chile) and Soprole SA (Santiago, Chile) is gratefully acknowledged. Special thanks to Hernán Vega (Soprole, Chile) and Angelica Horst (Danisco, Chile) for supporting this study. The authors thank Sixto Ibarra and Maxine Bober (Universidad San Luis Gonzaga de Ica, Peru) for their help in this research work.

\section{REFERENCES}

AOAC. 1990. Official Methods of Analysis. 15th ed. Association of Official Analytical Chemists International, Gaithersburg, MD.

Chandan, R. C., ed. 2006. Manufacturing Yogurt and Fermented Milks. John Wiley \& Sons, New York, NY.

Cross, M. L., R. R. Mortensen, J. Kudsk, and H. S. Gill. 2002. Dietary intake of Lactobacillus rhamnosus HN001 enhances production of both Th1 and Th2 cytokines in antigen-primed mice. Med. Microbiol. Immunol. (Berl.) 191:49-53.

De Keersmaecker, S. C., K. Braeken, T. L. A. Verhoeven, M. Perea Vélez, S. Lebeer, J. Vanderleyden, and P. Hols. 2006. Flow cytometric testing of green fluorescent protein-tagged Lactobacillus rhamnosus GG for response to defensins. Appl. Environ. Microbiol. 72:4923-4930.

de Man, J. C., M. Rogosa, and M. E. Sharpe. 1960. A medium for the cultivation of Lactobacilli. J. Appl. Microbiol. 23:130-135.

Domper, A. 1997. Efectividad de un Cultivo Protector (Biol. Profit) en la elaboración del yogurt batido. BSc Thesis. Departamento de Análisis Sensorial y Desarrollo de Productos, Universidad de Chile, Santiago, Chile.

Doyle, M. P., and L. R. Beuchat, editors. 2007. Food Microbiology: Fundamentals and Frontiers. 3rd ed. ASM Press, Washington, DC

Evrard, B., S. Coudeyras, A. Dosgilbert, N. Charbonnel, J. Alamé, A. Tridon, and C. Forestier. 2011. Dose-dependent immunomodulation of human dendritic cells by the probiotic Lactobacillus rhamnosus Lcr35. PLoS ONE 6:e18735.

Galvão, L. C., M. I. Fernandes, and R. Sawamura. 1995. [Lactose content and beta-galactosidase activity in yogurt, cheeses and curdled milk made in Brazil]. Arq. Gastroenterol. 32:8-14.

Gill, H., and J. Prasad. 2008. Probiotics, immunomodulation, and health benefits. Adv. Exp. Med. Biol. 606:423-454.

Gill, H. S., and K. J. Rutherfurd. 2001. Viability and dose-response studies on the effects of the immunoenhancing lactic acid bacterium Lactobacillus rhamnosus in mice. Br. J. Nutr. 86:285-289.

Gill, H. S., K. J. Rutherfurd, and M. L. Cross. 2001a. Dietary probiotic supplementation enhances natural killer cell activity in the elderly: An investigation of age-related immunological changes. J. Clin. Immunol. 21:264-271.

Gill, H. S., K. J. Rutherfurd, J. Prasad, and P. K. Gopal. 2000. Enhancement of natural and acquired immunity by Lactobacillus rhamnosus (HN001), Lactobacillus acidophilus (HN017) and Bifidobacterium lactis (HN019). Br. J. Nutr. 83:167-176.
Gill, H. S., Q. Shu, H. Lin, K. J. Rutherfurd, and M. L. Cross. 2001b. Protection against translocating Salmonella typhimurium infection in mice by feeding the immuno-enhancing probiotic Lactobacillus rhamnosus strain HN001. Med. Microbiol. Immunol. (Berl.) 190:97-104.

Gopal, P. K., P. A. Sullivan, and J. B. Smart. 2001. Utilisation of galacto-oligosaccharides as selective substrates for growth by lactic acid bacteria including Bifidobacterium lactis DR10 and Lactobacillus rhamnosus DR20. Int. Dairy J. 11:19-25.

Gutschmidt, J. 1951. Über die organoleptische Bewertung von Lebensmitteln mit Hilfe des Karlsruher Bewertungsschemas [The sensory scoring of foods with the aid of the Karlsruhe scoring system]. Dtsch. Lebensmitt. Rundsch. 11:244-251.

Hekmat, S., and G. Reid. 2006. Sensory properties of probiotic yogurt is comparable to standard yogurt. Nutr. Res. 26:163-166.

Hertzler, S. R., B.-C. L. Huynh, and D. A. Savaiano. 1996. How much lactose is low lactose? J. Am. Diet. Assoc. 96:243-246.

Kleyn, D. H., and J. R. Trout. 1984. Enzymatic-ultraviolet method for measuring lactose in milk: Collaborative study. J. Assoc. Off. Anal. Chem. 67:637-640.

Laaksonen, M. M. L., V. Mikkila, L. Rasanen, R. Rontu, T. J. Lehtimaki, J. S. A. Viikari, and O. T. Raitakari. 2009. Genetic lactase non-persistence, consumption of milk products and intakes of milk nutrients in Finns from childhood to young adulthood. Br. J. Nutr. 102:8-17.

Labuza, T. P. 1982. Shelf-life Dating of Foods. Vol. 1. 1 ed. Food \& Nutrition Press Inc., Westport, CT.

Labuza, T. P., and M. K. Schmidl. 1985. Accelerated shelf-life testing of foods. Food Technol. 39:57-62.

Lloyd, M. L., and W. A. Olsen. 1995. Disaccharide malabsorption. Pages 1087-1100 in Bockus Gastroenterology. W. S. Haubrich, F. Schaffner, J. E. Berk, and H. L. Bockus, ed. Saunders, Philadelphia, PA.

Matijević, B., K. Lisak, R. Božanić, and L. Tratnik. 2011. Impact of enzymatic hydrolyzed lactose on fermentation and growth of probiotic bacteria in whey. Mljekarstvo 61:154-160.

Mikelsaar, M., R. Mander, and E. Sepp. 1998. Lactic acid microflora in the human microbial ecosystem and its development. Pages 279 342 in Lactic Acid Bacteria: Microbiology and Functional Aspects. 2nd ed. S. Salminen and A. von Wright, ed. Marcel Dekker, New York, NY.

Moskowitz, H. R. 1983. Product Testing and Sensory Evaluation of Foods: Marketing and R\&D Approaches. Vol. 1. 1st ed. Food \& Nutrition Press, Westport, CT.

Nagaraj, M., B. Sharanagouda, H. Manjunath, and M. Manafi. 2009. Standardization of different levels of lactose hydrolysis in the preparation of lactose hydrolyzed yoghurt. Iranian Journal of Veterinary Research, Shiraz University 10:132-136.

O'Leary, V., and J. Woychik. 1976. A comparison of some chemical properties of yogurts made from control and lactase-treated milks. J. Food Sci. 41:791-793.

Olson, D. W., and K. J. Aryana. 2008. An excessively high Lactobacillus acidophilus inoculation level in yogurt lowers product quality during storage. Food Sci. Technol. 41:911-918.

Østlie, H. M., M. H. Helland, and J. A. Narvhus. 2003. Growth and metabolism of selected strains of probiotic bacteria in milk. Int. J. Food Microbiol. 87:17-27.

Ouwehand, A., E. Isolauri, and S. Salminen. 2002. The role of the intestinal microflora for the development of the immune system in early childhood. Eur. J. Nutr. 41(Suppl. 1):I32-I37.

Paulus, K., J. Gutschmidt, and A. Fricker. 1969. The Karlsruhe grading system-Development, application and modification. Lebensm. Wiss. Technol. 2:132-139.

Prescott, S. L., K. Wickens, L. Westcott, W. Jung, H. Currie, P. N. Black, T. V. Stanley, E. A. Mitchell, P. Fitzharris, R. Siebers, L. Wu, and J. Crane. 2008. Supplementation with Lactobacillus rhamnosus or Bifidobacterium lactis probiotics in pregnancy increases cord blood interferon- $\gamma$ and breast milk transforming growth factor- $\beta$ and immunoglobin A detection. Clin. Exp. Allergy 38:1606-1614. 
Savaiano, D. A., A. AbouElAnouar, D. E. Smith, and M. D. Levitt. 1984. Lactose malabsorption from yogurt, pasteurized yogurt, sweet acidophilus milk, and cultured milk in lactase-deficient individuals. Am. J. Clin. Nutr. 40:1219-1223.

Shaukat, A., M. D. Levitt, B. C. Taylor, R. MacDonald, T. A. Shamliyan, R. L. Kane, and T. J. Wilt. 2010. Systematic review: Effective management strategies for lactose intolerance. Ann. Intern. Med. 152:797-803.

Sheih, Y.-H., B.-L. Chiang, L.-H. Wang, C.-K. Liao, and H. S. Gill. 2001. Systemic immunity-enhancing effects in healthy subjects following dietary consumption of the lactic acid bacterium Lactobacillus rhamnosus HN001. J. Am. Coll. Nutr. 20(Suppl.):149-156.

Shu, Q., and H. S. Gill. 2002. Immune protection mediated by the probiotic Lactobacillus rhamnosus HN001 (DR20) against Escherichia coli O157:H7 infection in mice. FEMS Immunol. Med. Microbiol. 34:59-64.

Swagerty, D. L. Jr., A. D. Walling, and R. M. Klein. 2002. Lactose intolerance. Am. Fam. Physician 65:1845-1850.

Téllez-Luis, S. J., A. B. Moldes, J. L. Alonso, and M. Vázquez. 2003. Optimization of lactic acid production by Lactobacillus delbrueckii through response surface methodology. J. Food Sci. 68:1454-1458.

Toba, T., K. Arihara, and S. Adachi. 1986. Quantitative changes in oligosaccharides during fermentation and storage of yogurt inoculated simultaneously with starter culture and $\beta$-galactosidase preparation. J. Dairy Sci. 69:1241-1245.

Toba, T., A. Watanabe, and S. Adachi. 1983. Quantitative changes in sugars, especially oligosaccharides, during fermentation and storage of yogurt. J. Dairy Sci. 66:17-20.

Torriani, S., F. Gardini, M. E. Guerzoni, and F. Dellaglio. 1996. Use of response surface methodology to evaluate some variables affecting the growth and acidification characteristics of yoghurt cultures. Int. Dairy J. 6:625-636.

Wickens, K., P. N. Black, T. V. Stanley, E. Mitchell, P. Fitzharris, G. W. Tannock, G. Purdie, and J. Crane. 2008. A differential effect of 2 probiotics in the prevention of eczema and atopy: A doubleblind, randomized, placebo-controlled trial. J. Allergy Clin. Immunol. 122:788-794.

Wilt, T. J., A. Shaukat, T. Shamliyan, B. C. Taylor, R. MacDonald, J. Tacklind, I. Rutks, S. J. Schwarzenberg, R. L. Kane, and M. Levitt. 2010. Lactose intolerance and health. Evid. Rep. Technol. Assess. (Full. Rep.) 192:1-410.

Xu, S., T. D. Boylston, and B. A. Glatz. 2006. Effect of inoculation level of Lactobacillus rhamnosus and yogurt cultures on conjugated linoleic acid content and quality attributes of fermented milk products. J. Food Sci. 71:C275-C280.

Zhong, Y., M. G. Priebe, R. J. Vonk, C.-Y. Huang, J.-M. Antoine, T. He, H. J. M. Harmsen, and G. W. Welling. 2004. The role of colonic microbiota in lactose intolerance. Dig. Dis. Sci. 49:78-83.

Zhou, J. S., P. K. Gopal, and H. S. Gill. 2001. Potential probiotic lactic acid bacteria Lactobacillus rhamnosus (HN001), Lactobacillus acidophilus (HN017) and Bifidobacterium lactis (HN019) do not degrade gastric mucin in vitro. Int. J. Food Microbiol. 63:81-90.

Zhou, J. S., K. J. Rutherfurd, and H. S. Gill. 2005. Inability of probiotic bacterial strains Lactobacillus rhamnosus HN001 and Bifidobacterium lactis HN019 to induce human platelet aggregation in vitro. J. Food Prot. 68:2459-2464.

Zhou, J. S., Q. Shu, K. J. Rutherfurd, J. Prasad, M. J. Birtles, P. K. Gopal, and H. S. Gill. 2000a. Safety assessment of potential probiotic lactic acid bacterial strains Lactobacillus rhamnosus HN001, Lactobacillus acidophilus HN017, and Bifidobacterium lactis HN019 in BALB/c mice. Int. J. Food Microbiol. 56:87-96.

Zhou, J. S., Q. Shu, K. J. Rutherfurd, J. Prasad, P. K. Gopal, and H. S. Gill. 2000b. Acute oral toxicity and bacterial translocation studies on potentially probiotic strains of lactic acid bacteria. Food Chem. Toxicol. 38:153-161. 